\title{
Idioms of Multiculturalism, Multilingualism and Intercomprehension in the European Union
}

\author{
Lumturie Bajrami \\ South East European University, Tetovo \\ E-mail: I.bajrami@seeu.edu.mk
}

\author{
Doi:10.5901/ajis.2012.v2n4p39
}

\begin{abstract}
:
Europe is a continent of different and a big number of cultures, and on those basis is founded the European Union, as a unity of different nationalities, religions, cultural background, and a fundamental and the most important part of every ones identity is the language. Today Europe is home of millions of people which not only have their origins from Europe, but also is a home of many people who are forming two main groups of minorities, the emigrant minority and the regional minority. A functional multilingual and multicultural society requires willingness on the behalf on the linguistic participating groups to make compromises and to accept some linguistic standardization. Plurilingualism and intercomprehension are concepts of particular importance in the multilingual and multicultural European context. These are the main aims and requirements of the European Union when identifying and pursuing the fundamental objectives, which are done by promoting the definition of respecting cultural diversity and establishing a single 'European identity'. Inter comprehension, plurilingualism, intercultural communicative competence and democratic citizenship are concepts of particular importance in the multilingual and multicultural European context also. The European Union and the Council of Europe have identified and pursued the political objectives of social cohesion, by promoting the definition of a European social identity, which respects the diversity of national identities.
\end{abstract}

Key words: inter comprehension, language policy, European Union, multiculturalism

\section{Introduction}

Nowadays the EU is a union of many cultures, languages and tradition. History and practice of the institutional functioning of a large diversity of languages is shown as successful, that's why in many cases European Union is taken as an example of haw languages and cultures can mingle and function together in communities which have a diverse ethnic background.

The unanimous decision of the Council related to the language policy is reflected in the article 217 of the European Economic Community Treaty and article 192 of Euratom Treaty and developed on Council's Regulation N.1 provides to date for all twenty three official languages and working languages of all countries. With every new accession Regulation N.1 is amended. Each one of the main institutions of European Union has its own bylaws which regulate the working languages for their internal use.

The linguistic regime of the institutions of the EU was established in the first regulation ever passed by the Council of Ministers of the European Economic Community (EEC) in 1958. Regulation 1 stipulates the official and working languages of the European Communities. Although a distinction is made between official and working languages, no definition of the two concepts is provided. It is unclear when or which languages should be used: in other words, the list of languages does not necessarily imply that all languages should be used all the time.

The texts that give information do not state clearly which language is usually used for oral communication.

There is freedom, which is clear that institutions and agencies can be organized on their daily basis and without any disputes to function with the policy of multilingualism and multiculturalism. 


\section{Literature review}

Inhabitants of this part of the word don't only speak the main official languages which are 23 with the last enlargements, but there are also many other languages which don't have the official status of a working language in the main institutions of EU. The plurality of languages gives rise to specific problems in social organization and the use of language in community. The plurality of languages and cultures in many cases can lead to many misunderstandings which come to a surface from the dominance that a language presenting one ethnic group can have over other languages. Such is the case with the English language dominance in the EU and worldwide, but on the other hand can be the dominance of other language over the others.

According to Robert Phillipson (2006) in his book English a cuckoo in the European higher education nest of languages he explains the way English language has become a real serious threat towards other languages. On the other hand the economic sphere has its importance and also universities and the research arena has a great deal of importance towards the way of using English as the language of business and research also. He addresses the question of whether English may be considered a cuckoo in the European higher education nest of languages.

English may be threatening the life of other languages, or at least occupying the territories that traditionally have been their preserve. It is not English per se which is the agent involved in such processes. It is of course the users of the language, whether as a first or second language, and the forces they represent. What we need therefore to consider is the implications of any language sharing territory with English in these times of intensive Europeanisation. Is the engagement with English harmonious, inspirational and dialectic, or is it a Darwinian struggle for survival?

According to his analysis the researchers have a great impact and responsibility towards their own language, because they don't use their language which might have been an influential one in different times and different communities such as French or German which have been traditionally influential languages, instead they use and give importance to English and build up knowledge society that European Union proclaims its commitment.

The wide spread of English as one of the most important language of global communication has become an element which worries many people, especially those who are representatives of those languages which have lost their international function to English. Some warn against the long-term effects of the increasing proficiency in English among speakers of other European languages on the future of these languages. Others frame the issue in terms of identities and power; they fear that the international lingua franca not only endangers the maintenance and the status of other languages but also threatens languagebased identities and marginalizes speakers of other language groups.

Some Member States (e.g., France) have adopted policies to regulate the use of English in public life. An additional problem from the EU perspective is that English is the official language of two Member States and the mother tongue of most citizens of these countries, giving them an invaluable advantage over other EU citizens. At the EU level, there is no overt policy against American English, but steps have been taken to maintain and promote linguistic diversity in the EU. The commitment of Member States to increase the number of foreign languages on the regular secondary school curriculum to two in order to enhance linguistic diversity was justified by the fear that English would otherwise become the only foreign language taught to European pupils.

\section{The language policy of European union}

There are different ways of comprehending the plurality of languages not only in institutional level in EU but also in the practical ways which they are used and the policies which apply towards the education system.

Some complain about the financial and organizational costs of multilingualism, while others worry about the threat to other languages posed by the growing use of international English as the lingua franca. Very 
often, the issue is seen as an unavoidable clash between the need to promote one common language to improve EU-wide communication and the wish to protect national linguistic identities.

Most analysis use theory of culture to show that there are various ways of understanding the plurality of languages in the EU and the policies to deal adequately with such plurality, especially when it comes to the regulation of language use in the EU institutions.

The increase in the number of the European Union's (EU) official and working languages has been one of the main issues raised by every enlargement. Every new Member State , except Cyprus, has added a new language to the previous, and today the official and working languages of the EU are 23. Of course, the EU, as was foreseeable, has adopted several technical and organisational measures in order to better cope with the every change. The Council, for example, has adopted a system of interpreting 'upon request' for the meetings of some preparatory groups (Council of the European Union, 2005) and the Parliament has recommended length restrictions for certain documents in order to reduce the need for translation (European Parliament, 2004a).

Michele Gazzola (2006) developed an analysis which assesses and gives some important ideas upon the European language regime and more importantly his analyses is more focused on the functioning of European Parliament as it is faced with the challenges of enlargement in different phases. He gives some analysis of possible as he calls them, scenario, and results are shown considering which scenario is evaluated and how. His results show that there is no language regime which is shown as the best suitable solution.

There are also different researchers which have centered much on what makes a good and successful language policy function and they also have given their approaches towards the language policy problems and issues which are given as ideas for the functioning of the policy of many languages as the institutional and working languages of EU.

In the working document 'Linguistic policy: further options' (Podesta' , 2001a), seven different language regimes were proposed. However, it is important to note that the models which were given, were conceived under the hypothesis of 21 official languages, because it was not sure if Cyprus would have been reunified before the enlargement, hence requiring the adoption of Turkish as one of the official languages.

The seven models proposed were:

1. Monolingualism: use of a single official and working language.

2. Nationalisation: maintenance of the pre-enlargement structure and simple transfer of financial responsibility alone to the Member States, or transfer of the complete workload to the Member States.

3. Reduced multilingualism: use of only six official and working languages.

4. Asymmetric systems: these make it possible to speak/write in all 21 official languages, but listen/read in only a limited number of languages (three options are considered: 20-1, 20-3 or 20-6).

5. Controlled multilingualism: this model was proposed to ensure that all Members of the European Parliament (MEPs) had the right to speak/write and to listen/read in the language that they prefer; the difference between this and pure multilingualism resides in the internal process of linguistic mediation. The controlled multilingualism model was based on the systematic adoption of management correctives, sometimes already in use in some multilingual meetings before enlargement, such as making use of bi-active interpretation for the new languages and gradually extending this system to the former 11 working languages, greater use of pivot languages (three in particular), and other measures such as remote interpretation or greater use of external freelance linguistic staff.

6. Full multilingualism with management correctives (henceforth 'corrected full multilingualism'): that was, the extension to all languages of the former system for 11 languages. Unfortunately, no more is said and therefore it is not specified how the existing management correctives would have been adapted and extended o the post-enlargement situation.

7. Pure full multilingualism with 20 languages, with no kind of management corrective. 


\section{Multilingualism, culture and rational choice}

There are not many analyses which are conducted upon the theoretical work on relations between languages at that level institutional level. One major exception is the analysis, based on rational choice theory, by the Dutch sociologist Abram de Swaan on the world constellation of languages. De Swaan (1993, 1998a, 1998b, 2002) frames the language constellation of Europe in terms of competition between languages. Although assessing the language constellation in any region of the world at any time is very much shaped by the prevailing political and economic configuration, he emphasizes the own dynamics of language competition. He presents a floral model with

English at the core of the world constellation of languages and smaller flowers around other regional languages of wider communication, such as Spanish in Latin America, Mandarin in China, Russian in Russia's "near abroad," French in West Africa, etc.

De Swaan speaks of a language constellation when language groups are more connected with each other than with outside language groups. The connections between language groups are multilingual speakers. Individuals differ regarding their repertoire of languages. Someone's repertoire consists of the language she/he masters. The concept of repertoire is also applied to languages based on the linguistic abilities of their speakers. This communication potential is the product of plurality and centrality. Plurality is the number of speakers with which direct communication is possible through the language(s) involved, as a proportion of the total number of speakers in the system, whereas centrality refers to the number of multilingual speakers of the language(s) involved, as a proportion of the total number of multilingual speakers. Central to De Swaan's argument is the assumption that "If and when people decide to add a language to their repertoire (and if they have a choice), they will opt for the language that will increase the communication potential, of their repertoire more than any other language would." (1993, p 246).

De Swaan is able to calculate the value of each repertoire. The language with the highest value is the one an outsider should learn first: it was French in 1970 (because English was not yet an official language of the EC) and English in 1980 and in 1990.7 A monolingual person in one EU language should learn the language that adds most to her/his communication potential-and this is English, or French for native speakers of English.

Despite problems regarding dilemmas between individual and collective interests and the delimitation of the relevant system of languages, the model seems to explain pretty well the rise of English/American English as language of transnational communication in the EU. But to explain the continuation of institutional multilingualism in EU institutions, De Swaan needs to posit two assumptions: (1) each state will prefer a regime that includes its own language to any regime without it, and (2) each state will prefer a regime with fewer languages to one with more. If languages are put up for elimination in order of their decreasing communication potential or value, a so-called voting cycle ensues. The exclusion of any language is supported by all Member States, except the one defending its own. De Swaan therefore concludes, "Under these conditions, the status quo is especially hard to change by any kind of majority vote or when vetoes are allowed" (De Swaan, 1998: appendix).

The communication potential of the languages does not explain why Member States want to maintain their language, apart from seemingly irrational status reasons. Indeed, the model implicitly assumes rational persons that want to enlarge their communication potential, as opposed to irrational ones, that is, those who let primordial identities lead their lives and who therefore stick to their mother tongue. Other reasons to learn, use a language (as well to refuse to learn or use a specific language) are dismissed as irrelevant anomalies. It comforts the commonsense idea that communication (a rational goal) and identity (an irrational need) are incompatible aims.

\section{The importance of culture and language}

Cultural issues also play a crucial role in the nations identity. The Treaty of Maastricht gave the Union the 
power to act in the fields of culture and training, though only in 'support' of actions undertaken by Member States (Articles 151 and 149 of the EC Treaty). Following this, greater attention was paid to cultural diversity and the plurality of languages, and efforts were made to protect and promote them as such. On the other hand, as Mayer and Palmowski have remarked, there is not a real common cultural identity within the EU and 'if anything, then, Europe's cultural hallmark has been precisely its heterogeneity and multiplicity' (Mayer and Palmowski, 2004: 582).

In this sense, external - and to a lesser extent, internal - multilingual communication can be seen as a facet of the support given by EU language and cultural diversity.

According to Ruth Wodak (1999), identity can be considered as a mutable process, largely constructed through discourse practices which are continually redefined and negotiated within and outside of the communities. The individual narratives reveal several of the collective thematic streams produced by the communities in order to claim or defend domains of power and interest.

All historical-natural languages, considered as internal linguistic systems, display equal potentialities; the essential difference between them is only given by evaluation.

Even though the primary focus of this analysis is the language, is important to mention the cultural measures which are taken by the European Union, to make the citizens aware of their European identity. The key requisites for creating a common identity are common education programs and including the importance which is given in learning of languages in education programs. The most relevant programs are Lingua, Erasmus, Socrates and Leonardo da Vinci.

The Lingua program pursues the diversification of foreign languages offered in training and educational programs rather than promoting one or two priority languages. Erasmus is an international exchange program between universities meant to foster international understanding as well as multilingualism. Socrates and Leonardo da Vinci, are targeted at vocational trainees and high school students. This is an attempt to ensure that foreign language proficiency is not reserved for an elite or those who acquire it on account of their geographical and political position.

\section{Foreign language teaching policy}

What is the influence of EU policy concerning languages and language use on the teaching of foreign languages in the member states? Even if the EU plays no direct influence on language teaching policy in the member states, perhaps the actual use of languages in the institutions of the EU has a determining influence on foreign language teaching in the member states.

The EU as such is not concerned with the educational policies of member states, and the EU therefore has no policy on foreign language teaching.

The Council of Ministers makes regular pronouncements on foreign languages and language teaching for example, that education in at least two foreign languages is desirable for all EU citizens - but these are actually no more than well-intentioned and non-binding appeals to member states ( e.g. van Els 2003).

Of course, in spite of all this, the EU can take particular measures that aim at the improvement of foreign language teaching in member states. For example, it is the responsibility of the EU and every member state that optimal mobility of the citizens of all member states is guaranteed and that communication in a language other than the mother tongue forms no serious obstacle to this. The fact that the EU has set up particular programmes with this in mind and that it is developing particular instruments that can play a role in the process - such as the Common European Framework - is not only understandable but also desirable. It is also understandable that the socalled "small languages" should be granted a particularly privileged position. However, it seems that people sometimes go a little too far in this, and that the preoccupation with the multilingualism of the EU - that is, the concern for and about the "small languages" - sometimes takes on obsessive forms ( van Els 2003). Each member state is responsible for determining its own policy on foreign language teaching. The EU does not involve itself in this, as mentioned above. But the fact that the EU exists, with all that implies, does play a large role in the foreign language teaching policy of a member state. Any 
good policy on foreign language teaching will take as its point of departure the communicative needs of its own citizens. We must not forget, of course, that other factors play a part, but these will not be considered here (van Els 2003). The need of the citizens of a particular member state for foreign language knowledge is always determined, at least in part, by the fact that this state is a member of the EU. Only a small component of this derives from contacts with EU institutions; ultimately it is a question of a limited elite group of citizens who have direct dealings with these institutions.

The institutional language policy and the institutional use of languages therefore have only limited significance for the foreign language teaching policy of member states. In another perhaps equally important respect, the needs of the citizens of member states are determined by their contacts with countries outside the $\mathrm{EU}$, but most importantly the use of foreign lanaguges is on the benefit of every single person in EU, for the working, economic and social benefits in their own country or other countries also.

Whatever the relation between these two areas of need may be, it is primarily the needs of individual citizens - this must be emphasised - which have most influence on the foreign language teaching policies of memberstates. In EU declarations the intention is often expressed of making the EU and its citizens multilingual. In this context member states are frequently advised to require their citizens to learn at least the languages of neighbouring countries. There is certainly something to be said for this. The underlying argumentation, however, seems to be that in this way it can be ensured that all EU languages will appear in at least some school curricula: the "small languages" - and not just always English - will also be learned somewhere.

The argumentation seems to be: the more different languages that are learned, the more multilingual the EU will become. Moreover, if the "small languages" can also be learned in this way, they will at least continue to be safeguard against dying out and the EU will lose none of its multilingualism.

It is important that individuals have knowledge of foreign for their individual matter and interest, not that the curricula or the education programs have offered so. This is a matter of the communicative competence of the citizens themselves, of their mobility and their capacity for mutual understanding. It is not a matter of sustaining particular languages for their own sake.

\section{Functioning of multiculturalism in the education system of Macedonia}

There are a few basic analyses about multiculturalism and the relations between different ethnic groups in Macedonia and the way that diversity of culture and language is used in the education system of the country. This analysis will try to show the actual functioning and the importance given to multiculturalism in the education system and the capacity that the system uses in order to promote and insure tolerance and acceptance between different ethnical backgrounds and analyses more the perception and the levels of communication between students, parents, teachers which come from different ethnic groups. This is done to see the differences and look for better cooperation between all the parties involved in the community.

One of the important goals and aims of the country for longer time is creating the image of an educative system and of a country where differences are respected, and that every human has the right to be educated no matter which ethnic background it belongs, especially making sure that each students learns in his or her mother tongue. This was done successfully with the promotion of decentralization process where different ethnic groups gained more controls over the schools.

In order to promote the differences of culture, religious and language background there are many programs which support those initiatives which have as a base the tolerance and acceptance of differences between ethnicities.

Often it is said that the relations between people from different even backgrounds is the foundation to what is the future. Building relationships with people from different cultures is the key, to building diverse communities, which are powerful enough to achieve significant goals which are important to the future of one country. In this case the future of the country in European Union or in the North Atlantic Treaty Organization. 
The study provides additional insights into multiculturalism and inter-ethnic relations in education in several areas and Many programmes supported by the government and the legal and policy framework do serve to advance inter-ethnic communication, their focus until now has been on the prohibition of discrimination rather than the positive promotion of multicultural principles.

The prevailing understanding of respect, tolerance and acceptance of differences has been limited in its application to the use of different languages and support for the development

of different ethnic identities (e.g. through the encouragement to learn the languages of other ethnic communities in the country, e.g. Albanian, Turkish, Serbian), at least at the level of basic communication. The study of these languages should be given also a part on the task of priorities rather than always using foreign languages and all the importance is laid on the most influential languages of the time. The study of languages which belong to communities of the country is a initiative supported only by the private institutions, such as the case of universities, but that is not done in the state educational level, where students would have a choice to learn a language of their next door neighbor.

\section{Conclusion}

EU has many languages as official and working ones. Therefore the language policy merits considerable attention, but the preserving and promoting of one language should be on the hands of individuals which use and interact with a certain one. Improving your own communication skills by learning only one language in most of the cases English, is only one of the options available. The linguistic issues are generally framed as dilemma between communication and identity, and by promoting and preserving all languages as the most important part of identity is also protected and safeguarded the culture of each one of the member states and the language and identity they represent. It is also important the role that applied linguists have to play in the debate on the language policy of the EU. It is not easy to get a response to linguistic arguments from those who determine policy. In matters of language everyone freely considers himself to be an expert. Moreover, political factors other than the purely linguistic ones are involved. However it may be, linguists with social interests should not stop making their specialist knowledge available; nor should they refrain from continuing to fight against all the rhetoric and all the myths that are associated with multilingualism.

\section{References}

Phillipson, Robert (2006) “English only Europe- Challenging language policy” London/New York: Routledge.

Phillipson, Robert (2003) "English a a cucoo in the European higher education nest of languages"

Van Els, Theo (2005) "The European Union, its institutions and its langauges, a language political observation"

Mamadoouh, Virginie (1999) " Beyond nationalism: Three visions of the European Union and thier implications for the linguisitc regime of its institutions"

Gazzola,Michelle (2006) "Managing multilingualism in the European Union: Language policy evaluation for the European Parliament"

van Els, T.J.M. (2001) The European Union, its institutions and its languages: some language political observations. Current Issues in Language Planning 2.4: 311-60.

European Commission (1999) Eurobarometer. Public opinion in the European Union. Report no. 50. Brussels: European Commission.

European Convention (2003) Treaty establishing a constitution for Europe. Draft.Luxembourg: Office for Official Publications of the European Communities.

Paulston, C.B. (1998) Linguistic minorities in multilingual settings. Amsterdam

Eurobarometer (2006a) 'Europeans and their Languages', No. 243. Survey of 38,694 persons in 29 European countries between 5 November and 7 December 2005. Results weighted by population (Brussels: Eurobarometer).

de Swaan, Abram. (1993). "The Evolving European Language System: A Theory of Communication

Potential and Language Competition." International Political Science Review 14(3), 241-256.

de Swaan, Abram. (1998b). "The European Language Constellation." In Proceedings of the Conference"Which languages for Europe?" Oegstgeest, The Netherlands, 9-11 October 1998. 
de Swaan, Abram. (2002). Words of the World: The Global Language System. Cmbridge polity

Wodak, R., de Cillia, R., Reisigl, M. and Liebhart, K. (1999) The Discursive Construction of National Identity. Edinburgh: Edinburgh University Press.

European Parliament (2004a). Code of Conduct on Multilingualism. E 338.978/BUR. Brussels: European Parliament.

European Parliament (2004b). Translation and Edition. Parliamentary Documents-Questions and Answers. Brussels: Directorate-General-Translation and edition.

Mayer, Franz, C. \& Palmowski, Jan (2004). European identities and the EU - the ties that bind the peoples of Europe. Journal of Common Market Studies, 42(3), 573-598.

European Comission (Eurobarometer) Public opinion in the European Union

European Journal of Political Economy

Europa: Summaries of EU legisation

Council of Europe (2005)European Charter for Regional and Minority languages

Council of Europe (2004)European Charter for Regional and Minority languagesEBLUL: European Bureau for Lesser Used Languages - United in diversity. 